\title{
Multi-objective Optimization of Carbon/Glass Hybrid Composites with Newly Developed Resin (NDR) using Grey Relational Analysis.
}

\begin{abstract}
:
Purpose:

The focus of this research work is on the effect of design variables such as the carbon layer in stacking sequence, the use of different resins on the bonding strength of fibers, stacking angle of fibers and thickness of laminates on the mechanical properties of carbon/glass fiber hybrid composites. The mechanical properties are Tensile, Shear and 3-point Flexural strength. Carbon and Glass fibers have enchanting properties and excellent weight to strength ratio in comparison with the metals.

Methodology:

To determine the most significant design variable for optimum mechanical properties of the hybrid composite, the Taguchi Technique has been used. For this purpose, the $\mathrm{L}_{16}$ orthogonal array has been formed. The Signal to Noise $(\mathrm{S} / \mathrm{N})$ ratio plots was obtained to determine the effect of design variables on mechanical properties such as Tensile, Shear and 3-point Flexural strength. The statistical analysis was carried out by using the Analysis of Variance (ANOVA). Findings

Through this analysis, it was observed that different resins and stacking angles were the most significant factors for tensile, shear and flexural strength of hybrid composites. The contribution of resin and stacking angle was respectively $55.22 \%$ and $30.21 \%$ on tensile strength, $43.32 \%$ and $53.27 \%$ on shear strength and $75.55 \%$ and $20.67 \%$ on flexural strength at $95 \%$ confidence level. A multi-objective optimization was carried out using Grey Relational Analysis (GRA) to identify an optimum combination of design variables. The GRA shows that the optimal design variable setting for maximum tensile, shear and flexural strength is as A2B2C4D1. (i.e. Stacking sequence $\mathrm{G} / \mathrm{C} / \mathrm{G} / \mathrm{G}$, stacking angle is $45^{\circ}$, the type of resin is NDR and laminate thickness is $0.2 \mathrm{~cm}$ ). It is seen that the effect of the type of resin used is significant in the bonding strength of fibers.

Originality

Three conventional types of resins along with the newly developed resin (NDR) were studied for their effect on the tensile, shear and flexural strength of hybrid composites. The validation test was carried out at a selected set of optimum design variables A2B2C4D1. The test indicates an improvement in grey relational grade by $1.366 \%$ showing the tenacity of grey relational analysis. Also the NDR enhanced the mechanical properties for commercial applications like beam, tank wall etc.
\end{abstract}

Keywords: NDR; GRA; ANOVA; Hybrid; Carbon fiber; Glass fiber 


\section{Introduction:}

Composite materials are recognized for high specific modulus, high specific strength, high resistance to corrosion, low weight. They can be used in a wide range of applications like aerospace, automotive, marine, defense, drilling, biomedical, etc., giving them an advantage over traditional materials such as metals and ceramics. [1-11]. The mechanical properties of composite material are affected by the nature of fibers, type of resin, stacking angle, stacking sequence, and fiber volume percentage. Morye et al. [12] have shown that the aramid fibers with phenolformaldehyde and polyvinyl butyral (PVB) resins have greater tensile strength and modulus than nylon 66. Wong et al. [2] highlighted that E-glass fibers along with epoxy matrix have better mechanical properties than phenolic resin. Therefore, the mechanical properties of composite laminates depend on these design variables. Dong et al. [13-19] have analyzed the tensile and flexural properties of carbon/glass epoxy hybrid composite using experimental and FEA approach and have observed the positive effect of substituting the partial carbon fiber with glass fibers. Other researchers $[20,21]$ have studied the effect of epoxy and polyester resin on the tensile strength of the natural fiber. The effect of both the resins on the tensile strength of eucalyptus fiber has been investigated. They have also investigated the effect of epoxy resin with glass and curaua fiber. Jesthi and Nayak [22] analyzed the effect of different stacking sequences of glass and carbon fiber on tensile, flexural and impact strength of laminates for marine applications. It is observed that tensile strength was increased by $14 \%$ and flexural strength by $43 \%$ in the hybrid composite compared with the plain Glass fiber reinforced polymer composites (GFRPC). Some researchers [23-25] also have analyzed the effect of stacking sequence of carbon, glass, and basalt fiber hybrid composite on mechanical properties through analytical, numerical and experimental analysis. It is seen that the stacking sequence has the positive effect of hybridization. Kalantari et al. [26, 27] have worked on multi-objective robust optimization of unidirectional glass/carbon fiber for flexural loading. The posteriori approach was used to optimize the cost and weight by considering the thickness and fiber volume fraction as design variables. Senthil Kumar et al. [28] used the Taguchi technique for the optimization of tribological properties of nano clay/epoxy/ glass fibers. Some researchers [29, 30] have adopted the GRA approach to optimize the process parameters of WEDM for metal composites. The most significant parameters affecting the WEDM process have been analyzed. Ghasemi et al. [31] have used the response surface method for the optimization of mechanical properties for polypropylene/talc/graphene composites. The effect of three variables i.e. polypropylene, graphene, and maleic anhydride grafted polypropylene on the mechanical properties of composites has been analyzed. The glass fibers are recognized for their lower cost and carbon fibers are identified for its high strength to weight ratio. Some researchers [35, 36] have investigated the mechanical demeanor of fiber metal laminate (FML). They have used the titanium, aluminum metal to form a hybrid composite structure with carbon and glass fiber bonded by epoxy resin. Xinwie et al. [37] observed that tensile strength and elastic modulus of $\mathrm{Zn}-\mathrm{Al}$ alloy were improved by introducing the carbon fiber in the composite structure. Also, some researchers $[38,39]$ used the FEA approach to investigate the effect of stacking angle on the strength of the shaft.

From this brief literature review, it is seen that little amount of work on optimization of mechanical properties taking into consideration the combined effect of design variables such as 
stacking angle, stacking sequence, different resins, and thickness of composite laminates has been carried out. Also, a very little amount of work was carried out in the resin development. To determine the exact significance of these variables and to obtain the optimum combination the scientific approach must be used.

As such, the focus of this research work is on the optimization of the design variables like stacking angle, stacking sequence, different resins, and thickness of composite laminates which affect the mechanical properties of hybrid composites. For this purpose, the Taguchi technique and the method of Grey Relational Analysis (GRA) are used to identify the optimum combination of design variables. In this case, the effect of the above-mentioned design variables, particularly of the newly developed resin (NDR) on the mechanical properties of hybrid composites has been investigated.

From the existing literature, it is scrutinized that, the focus of current works of literature is to investigate the impact of single design variables on the mechanical properties of the composite. The real ongoing challenges in the industries are lack of statistics on the impact of various design variables on the strength of the composite laminate. This research supports to focus on the exact influence of variables on the mechanical strength of the composite laminate. Also, there is a lack of research to investigate the impact of resins on bonding strength. This research helps to investigate the effect of Newly Developed Resin on the strength of composite laminate compared with existing resins such as epoxy, polyester, and vinyl ester. After a brief investigation through the experimental results, it has been determined that the type of resin and stacking angle are the most significant factors on the Mechanical Properties of Composite laminate.

\section{Design variables:}

First of all, the necessary information for i) the mechanical properties of glass and carbon fibers selected for hybrid composite sample, ii) the types of resins selected to analyze the effect on mechanical properties and bonding strength of the fibers, and iii) stacking angle and stacking sequence are presented.

a) Fibers:

For reinforced composite laminate preparation two fibers were chosen, i.e. 200 GSM Carbon Fiber and 900 GSM Glass Fiber. Table 1 demonstrates the mechanical properties of these fibers.

Table 1. Mechanical properties of glass and carbon fiber

\begin{tabular}{clcc}
\hline Sr.No. & \multicolumn{1}{c}{ Specifications } & 900 GSM glass fiber & 200 GSM carbon fiber \\
\hline 1 & Modulus of elasticity $(\mathrm{MPa})$ & 70000 & 235000 \\
\hline 2 & Tensile Strength $(\mathrm{MPa})$ & 3500 & 3850 \\
\hline 3 & Density $\left(\mathrm{Kg} / \mathrm{m}^{3}\right)$ & 2700 & 1650 \\
\hline 4 & $\%$ elongation & 4.5 & 1.55 \\
\hline
\end{tabular}

\section{b) Resins:}

Four different resins were selected to analyze the effect on the mechanical properties of reinforced composite and bonding strength of the fibers. Three resins are conventional resins i.e. epoxy, vinyl ester and polyester and the fourth one is the Newly Developed Resin (NDR) from polyethylene and polyurea group. The NDR has been developed in SP Concare Pvt.Ltd. Sangli. (Maharashtra, India). Polyurea can be produced by reacting to a component that constitutes a Diisocyanate with a component that constitutes polyamine. The synthesis of NDR is shown in 
Fig. 1. The detailed formulation and contents to prepare a new resin are given in Table 2. The novelty of this research is the development of new resin called NDR and to investigate the effect of NDR on the bonding strength of the fiber.<smiles>CNC(=O)NC=NNC(=O)NNC(C)(C)C</smiles>

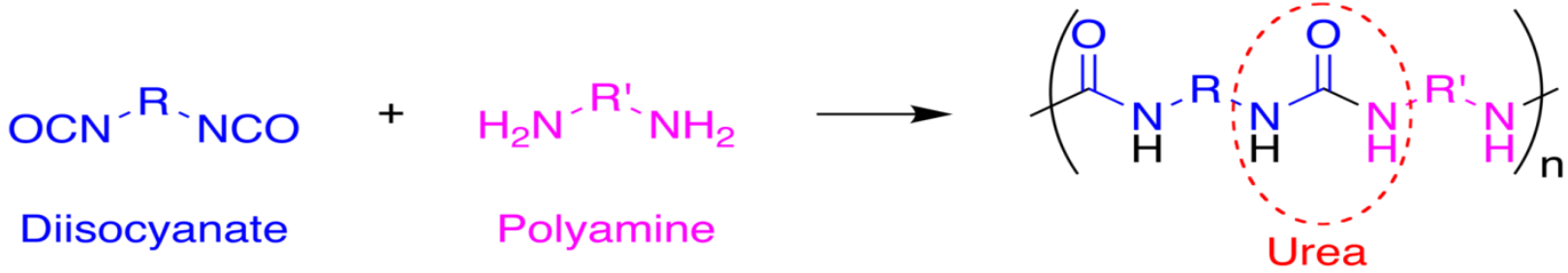

Fig.1 Synthesis of NDR

Table 2. Formulation and contents of NDR

\begin{tabular}{ccc}
\hline Sr. No. & Contents & Percentage \\
\hline 1 & Polyol & $47-52$ \\
\hline 2 & Barytes & $20-24$ \\
\hline 3 & Moisture Sieves & $5-7.5$ \\
\hline 4 & Pigment & $1.5-3.5$ \\
\hline 5 & Silica Powder & $0-1$ \\
\hline 6 & Hardner & $17-20$ \\
\hline
\end{tabular}

The tensile test was performed on resins according to ASTM D-412. The samples of resin are shown in Fig.2. These specimens were manufactured in the rubber mold. To determine the mechanical properties of resin five specimens for each resin were manufactured as per the ASTM D-412 standards. Fig. 2(a) shows the specimens of epoxy resin. Similarly, Fig 2(b), (c) and (d) indicate the specimens of vinyl ester, polyester, and NDR resins respectively.

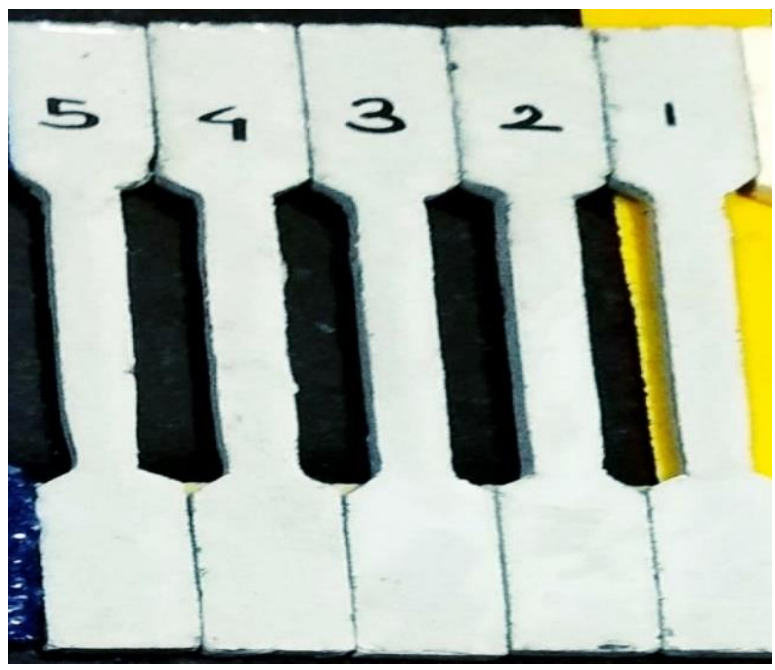

(a)Epoxy resin specimens

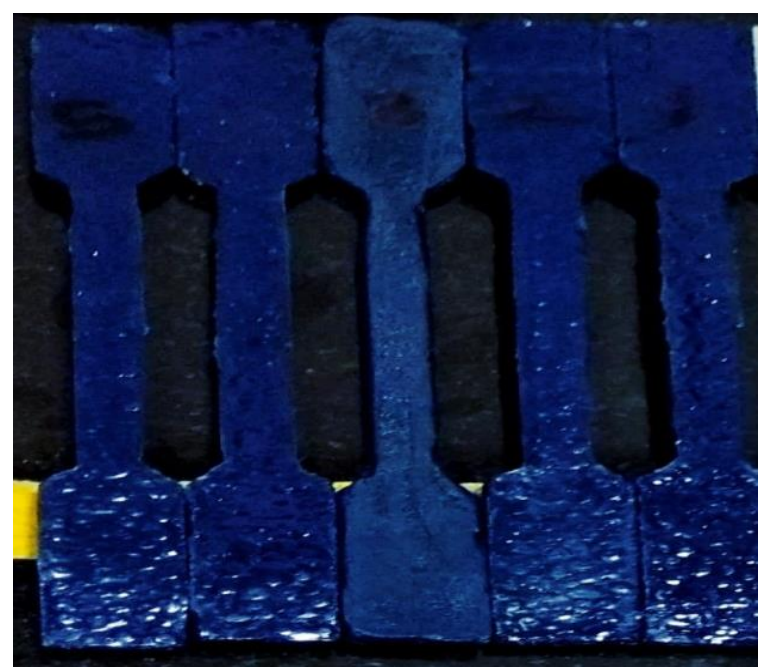

(b) Vinyl ester resin specimens 


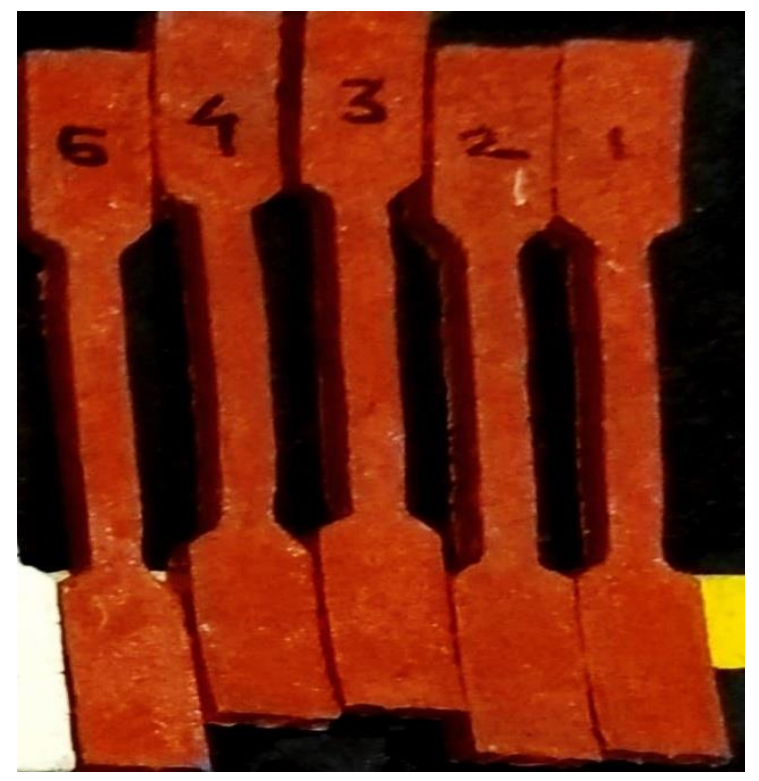

(c) Polyester resin specimens

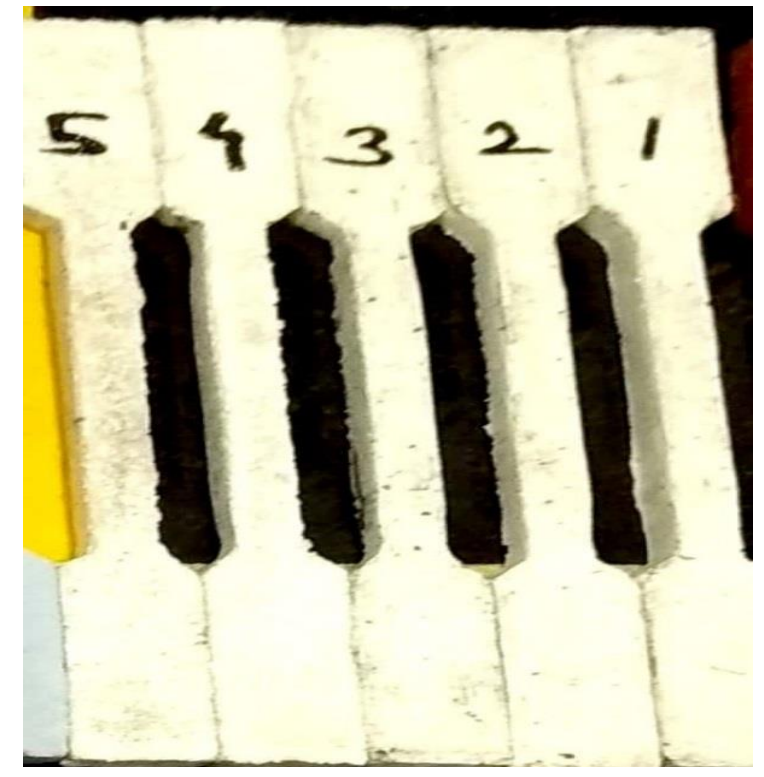

(d) NDR specimens Fig.2 (a) Epoxy resin (b) Vinyl ester resin (c) Polyester resin (d) NDR

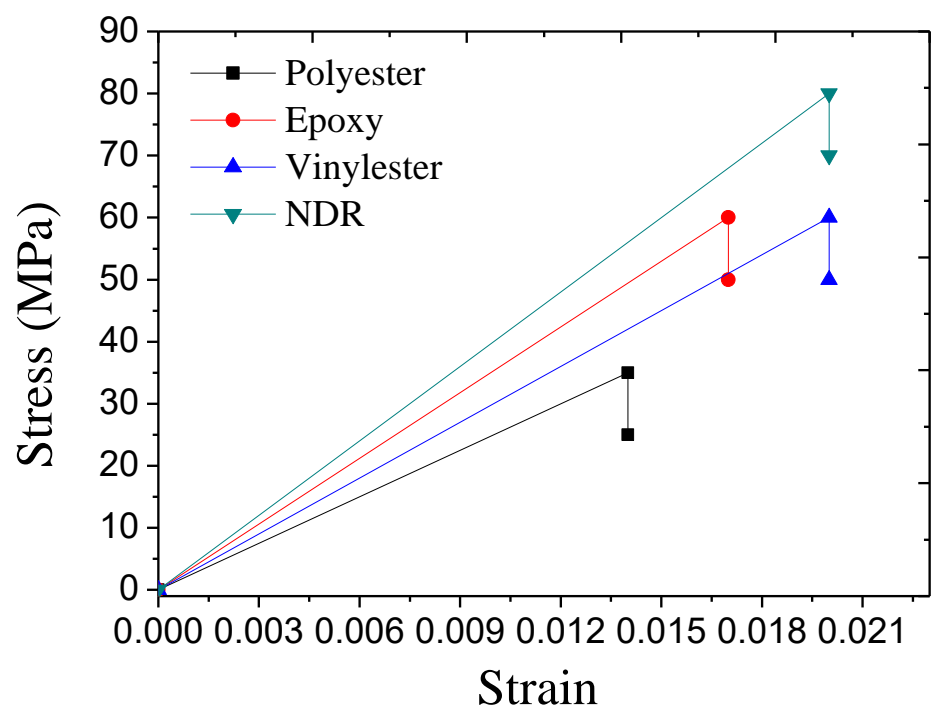

Fig.3 Comparative Graph of Stress vs. Strain for resins

The comparative results of stress vs. strain are illustrated in Fig.3. The NDR gives the highest strength compared to the other resins. The detail values of stress and strain are presented in Table 3. The cost of all resins indicates that NDR is cheaper for the industry and gives more strength compared with the other resin. The detailed properties for NDR after the investigation are represented in Table 4.

Table 3 Tensile Stress and Strain values for different resins

\begin{tabular}{|c|c|c|c|}
\hline Resin & Stress (MPa) & Strain & Cost in INR \\
\hline Epoxy & 60 & 0.017 & $500 / \mathrm{Kg}$ \\
\hline Polyester & 35 & 0.014 & $350 / \mathrm{Kg}$ \\
\hline Vinyl ester & 60 & 0.02 & $350 / \mathrm{Kg}$ \\
\hline NDR & 80 & 0.02 & $270 / \mathrm{Kg}$ \\
\hline
\end{tabular}


Table 4 Physical properties of NDR

\begin{tabular}{|c|c|c|c|c|}
\hline $\begin{array}{c}\text { Tensile Strength } \\
\text { (MPa) }\end{array}$ & $\begin{array}{c}\text { Flexural } \\
\text { Strength (MPa) }\end{array}$ & $\begin{array}{c}\text { Modulus of } \\
\text { Elasticity (MPa) }\end{array}$ & $\begin{array}{c}\text { Density } \\
\text { (Kg/Litre) }\end{array}$ & Viscosity (cps) \\
\hline $\mathbf{8 0}$ & $\mathbf{4 0}$ & $\mathbf{3 5 0 0}$ & $\mathbf{1 . 2 5}$ & $\mathbf{2 7 0 0}$ \\
\hline
\end{tabular}

\section{c) Stacking Angle:}

Four stacking angles $0^{0}, 45^{\circ}, 90^{\circ}$ and $135^{\circ}$ of carbon and glass fibers were selected to analyze the effect on mechanical properties.

d) Stacking Sequence:

In this research work, hybrid composite i.e. Glass and Carbon fibers were considered to investigate the effect of the carbon layer in the stacking sequence. As per ASTM standards, the thickness of the laminate must be maintained in certain laminate. So, to manufacture the laminate as per the ASTM standards the four layers are selected. Carbon fibers are costly than glass fibers. Hence, one layer has been manufactured with a carbon layer and three layers have been manufactured by glass fiber. The glass fiber is having a higher tensile strength compared with metal like steel. So, based on the fiber cost to strength ratio for the investigation the three layers of glass were incorporated. To investigate the exact effect carbon fiber on the strength of the laminate structure its sequence has been varied from the bottom layer to the top layer. The desire application for the manufactured laminated is useful to set the basic properties for the composite structure like a shaft, beams, etc.

\section{Design of Experiments using Taguchi Method}

In composite materials, the performance and reliability of any component depend upon the properties of the laminate. The design variables like stacking sequence, stacking angle, the bonding strength of resin and thickness strongly affect the properties of the composite laminates. To determine the exact effect of these design variables on the mechanical properties of laminate, the engineering approach is to decide the optimum combination of design variables. Taguchi method can be applied for the optimization of design variables to obtain optimum combination with the lower cost and a minimum number of experiments. The Taguchi method stands on the technique of matrix experiments, known as orthogonal array (OA). The OA was selected to achieve the optimum level of each design variable. According to the Taguchi method, the objective functions are classified into three categories, namely, "smaller the better type", "larger the better type" and "nominal the best type". The mechanical properties such as Tensile strength, Shear strength, and Flexural strength are to be maximized and hence 'larger the better type' objective function has been selected in the present study. The selected design variables and their recognized levels as per $\mathrm{L}_{16} \mathrm{OA}$ are presented in Tables 5 and 6 respectively.

Table 5.Design variables and their levels

\begin{tabular}{lccccc}
\hline Parameter & Code & Level 1 & Level 2 & Level 3 & Level 4 \\
\hline Stacking Sequence(A) & $\mathrm{StSq}$ & $\mathrm{C} / \mathrm{G} / \mathrm{G} / \mathrm{G}$ & $\mathrm{G} / \mathrm{C} / \mathrm{G} / \mathrm{G}$ & $\mathrm{G} / \mathrm{G} / \mathrm{C} / \mathrm{G}$ & $\mathrm{GGGC}$ \\
\hline Stacking Angle $\left({ }^{0}\right)(\mathrm{B})$ & $\mathrm{StAn}$ & 0 & 45 & 90 & 135 \\
\hline Resin $(\mathrm{C})$ & $\mathrm{Re}$ & Epoxy & Polyester & Vinyl ester & NDR \\
\hline Thickness $(\mathrm{cm})(\mathrm{D})$ & $\mathrm{Th}$ & 0.2 & 0.3 & & \\
\hline
\end{tabular}

Table 6.Design of Experiments using $\mathrm{L}_{16}$ orthogonal array 


\begin{tabular}{ccccc}
\hline $\begin{array}{c}\text { Experiment } \\
\text { Number }\end{array}$ & \multicolumn{4}{c}{ Levels of Design variables } \\
\cline { 2 - 5 } & StSq & StAn $\left({ }^{(}\right)$ & Re & Th(cm) \\
\hline 1 & $\mathrm{C} / \mathrm{G} / \mathrm{GG}$ & 0 & Epoxy & 0.2 \\
\hline 2 & $\mathrm{G} / \mathrm{C} / \mathrm{G} / \mathrm{G}$ & 45 & Epoxy & 0.2 \\
\hline 3 & $\mathrm{G} / \mathrm{G} / \mathrm{C} / \mathrm{G}$ & 90 & Epoxy & 0.3 \\
\hline 4 & $\mathrm{G} / \mathrm{G} / \mathrm{G} / \mathrm{C}$ & 135 & Epoxy & 0.3 \\
\hline 5 & $\mathrm{G} / \mathrm{C} / \mathrm{G} / \mathrm{G}$ & 0 & Polyester & 0.3 \\
\hline 6 & $\mathrm{C} / \mathrm{G} / \mathrm{G} / \mathrm{G}$ & 45 & Polyester & 0.3 \\
\hline 7 & $\mathrm{G} / \mathrm{G} / \mathrm{G} / \mathrm{C}$ & 90 & Polyester & 0.2 \\
\hline 8 & $\mathrm{G} / \mathrm{G} / \mathrm{C} / \mathrm{G}$ & 135 & Polyester & 0.2 \\
\hline 9 & $\mathrm{G} / \mathrm{G} / \mathrm{C} / \mathrm{G}$ & 0 & Vinyl ester & 0.2 \\
\hline 10 & $\mathrm{G} / \mathrm{G} / \mathrm{G} / \mathrm{C}$ & 45 & Vinyl ester & 0.2 \\
\hline 11 & $\mathrm{C} / \mathrm{G} / \mathrm{G} / \mathrm{G}$ & 90 & Vinyl ester & 0.3 \\
\hline 12 & $\mathrm{G} / \mathrm{C} / \mathrm{G} / \mathrm{G}$ & 135 & Vinyl ester & 0.3 \\
\hline 13 & $\mathrm{G} / \mathrm{G} / \mathrm{G} / \mathrm{C}$ & 0 & NDR & 0.3 \\
\hline 14 & $\mathrm{G} / \mathrm{G} / \mathrm{C} / \mathrm{G}$ & 45 & NDR & 0.3 \\
\hline 15 & $\mathrm{G} / \mathrm{C} / \mathrm{G} / \mathrm{G}$ & 90 & NDR & 0.2 \\
\hline 16 & $\mathrm{C} / \mathrm{G} / \mathrm{G} / \mathrm{G}$ & 135 & NDR & 0.2 \\
\hline
\end{tabular}

\section{Materials and Methods:}

\subsection{Fiber and Resins:}

The glass fibers and carbon fibers, the binding resins (epoxy, vinyl ester, and polyester) were purchased from SP Concare Pvt. Ltd. Sangli (Maharashtra India). These ingredients are used in aeronautical applications [32] and hence selected for this research work.

The special resin developed by SP Concare Pvt. Ltd. Sangli (Maharashtra India), known as NDR, is taken for the comparative analysis.

\subsection{Preparation of hybrid composite}

The hybrid composite laminates were prepared by hand layup method. The fibers were overlapped layer by layer and saturated with the resins in open mold and curing was done at ambient temperature. The air bubbles were removed by using a vacuum pump. The components were manufactured according to OA.

\subsection{Testing for Mechanical Properties:}

\subsubsection{Tensile Test:}

The tensile test was carried out on hybrid composite specimens of size 250x25 mm according to ASTM standard D3039. The universal testing machine (UTM) of capacity $1000 \mathrm{KN}$ with a crosshead speed of $2 \mathrm{~mm} / \mathrm{min}$ was used for testing the specimens. The tensile specimens and experimental setup are shown in Figures (4) and (5) respectively. These specimens were manufactured by hand layup method. The specimens were manufactured according to the $\mathrm{L}_{16}$ orthogonal array. The three design variables are having four levels and one design variable is having the two levels. Hence, to reduce the number of experimental trials and cost of experimentation the L16 orthogonal array according to Taguchi Approach was incorporated in this investigation. The UTM machine of Mechasoft, India was used to carry out the tensile test. 


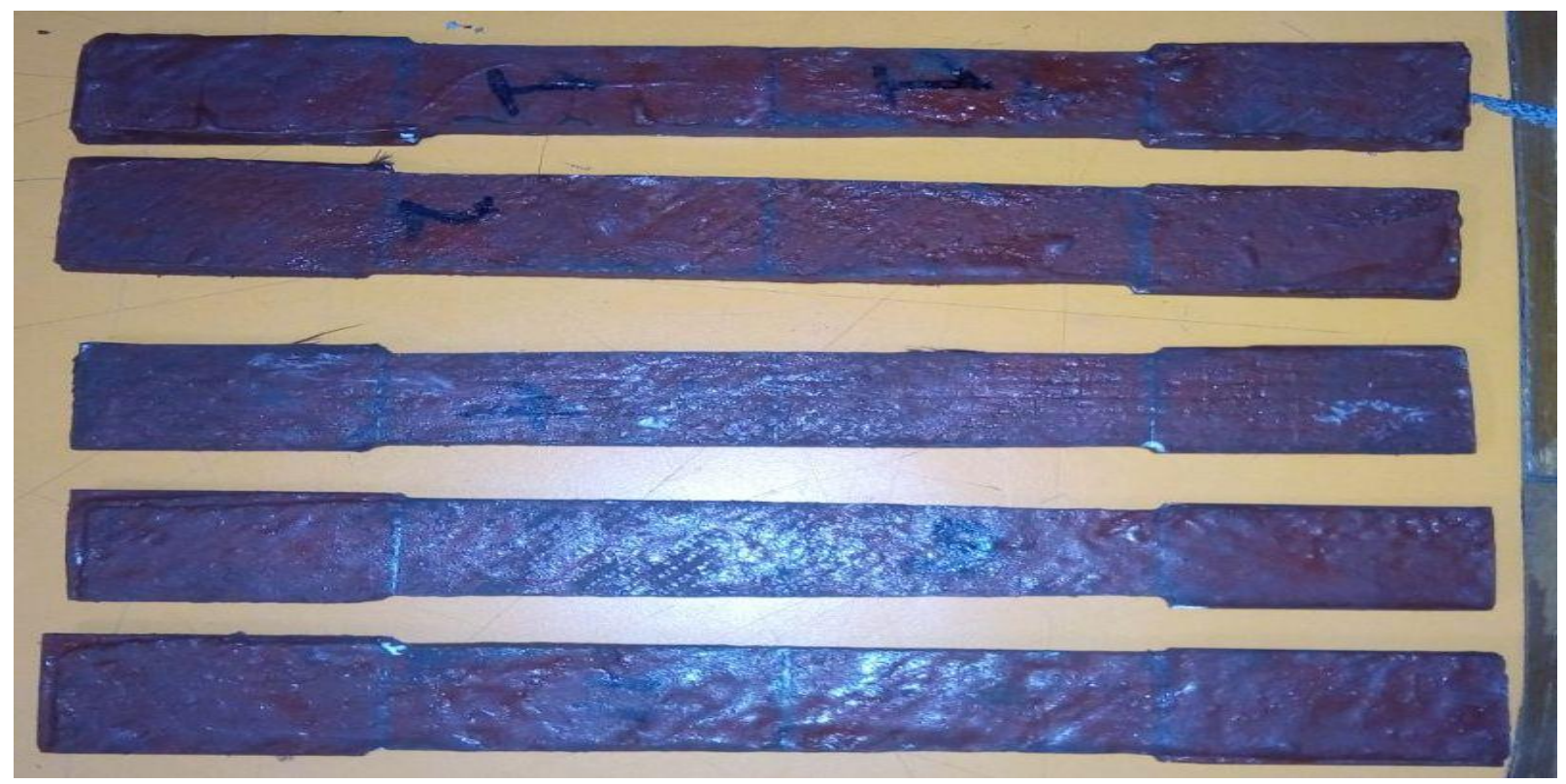

Fig.4 Sample of Tensile Test specimens.

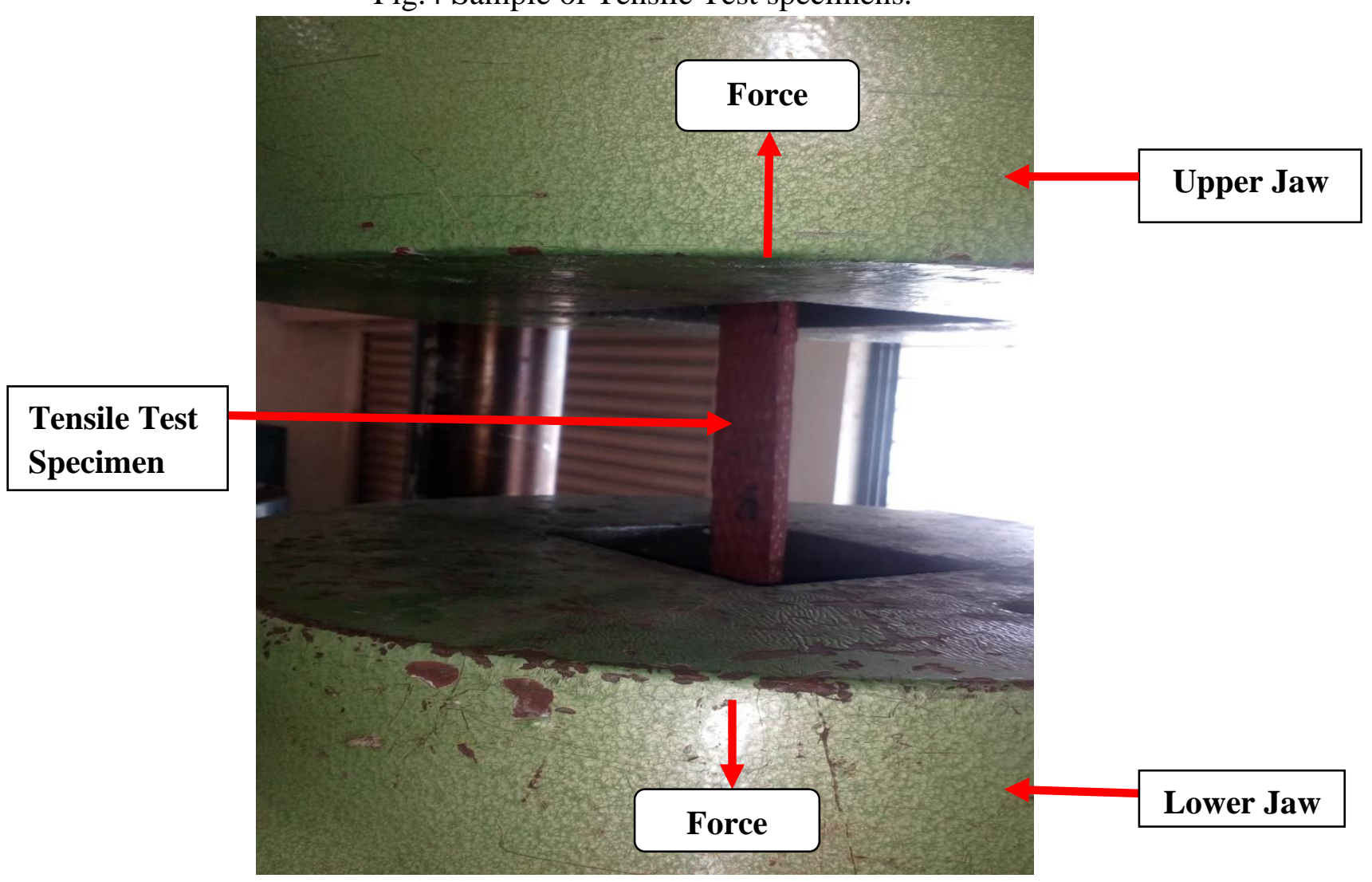

Fig.5 Experimental Setup for Tensile Test (UTM)

\subsubsection{Shear Test:}

The shear test was carried out on hybrid composite specimens of size $76 \times 20 \mathrm{~mm}$ according to ASTM standard D5379. The shear testing machine with a capacity of $100 \mathrm{KN}$ was used for testing. The shear test specimens and testing setup are shown in Fig. 6 and Fig.7 respectively. The shear test specimens were manufactured by hand layup method. The shear testing machine (Fig.7) of the Star testing system, India was used to conduct the experiments. 

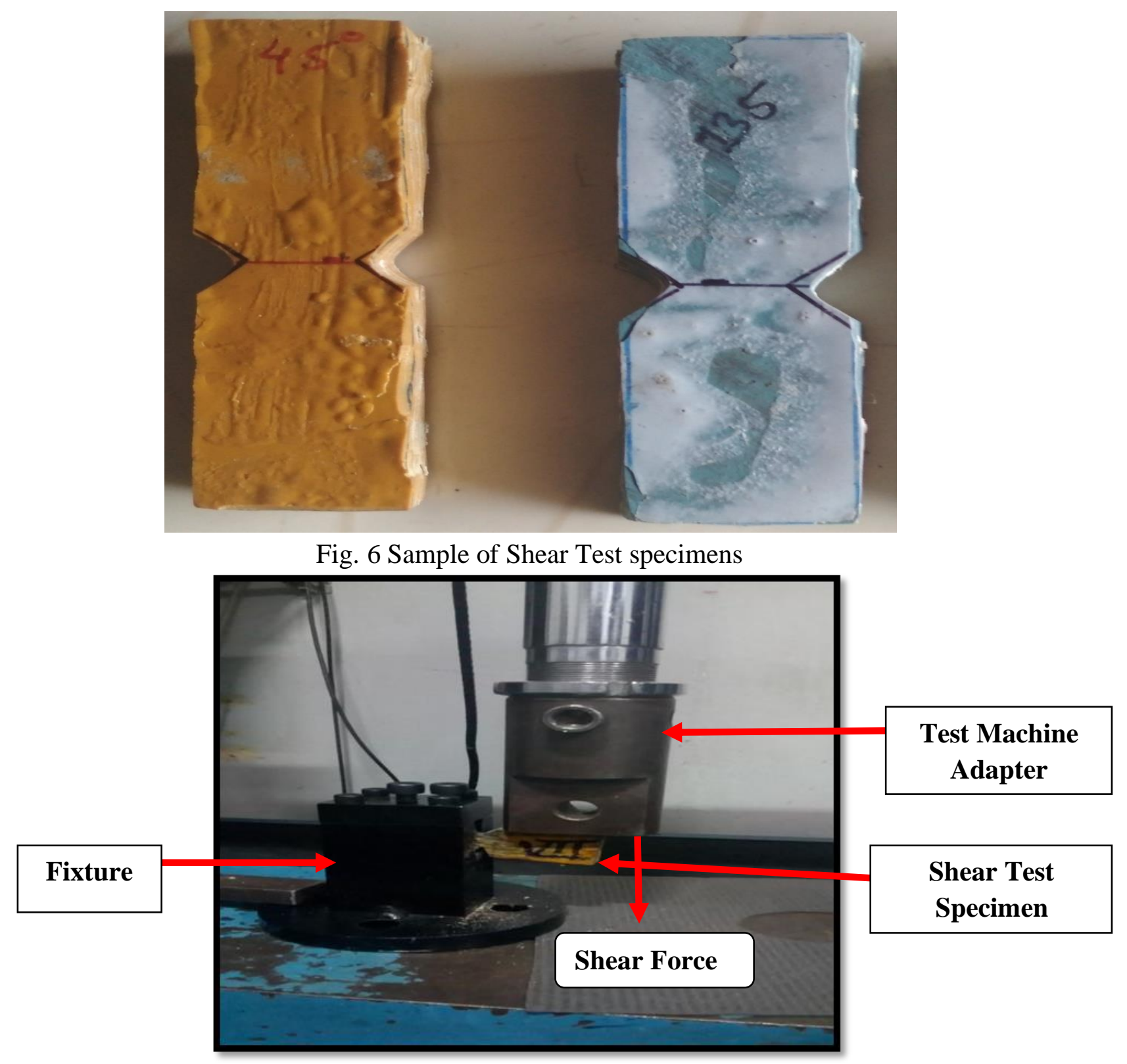

Fig.7 Experimental Setup for Shear Test

\subsubsection{3-Point Flexural Test:}

The size of the specimen for the flexural test was decided according to ASTM standard D790. The widths of the specimens were $12.7 \mathrm{~mm}$ and the span length was 16 times of thickness. The specimens were tested using a Universal testing machine (UTM) with a 50KN load cell. The sample specimens and testing setup are as shown in Fig.8 and Fig.9 respectively. The flexural test specimens (Fig.8) were also manufactured according to the hand layup method. 


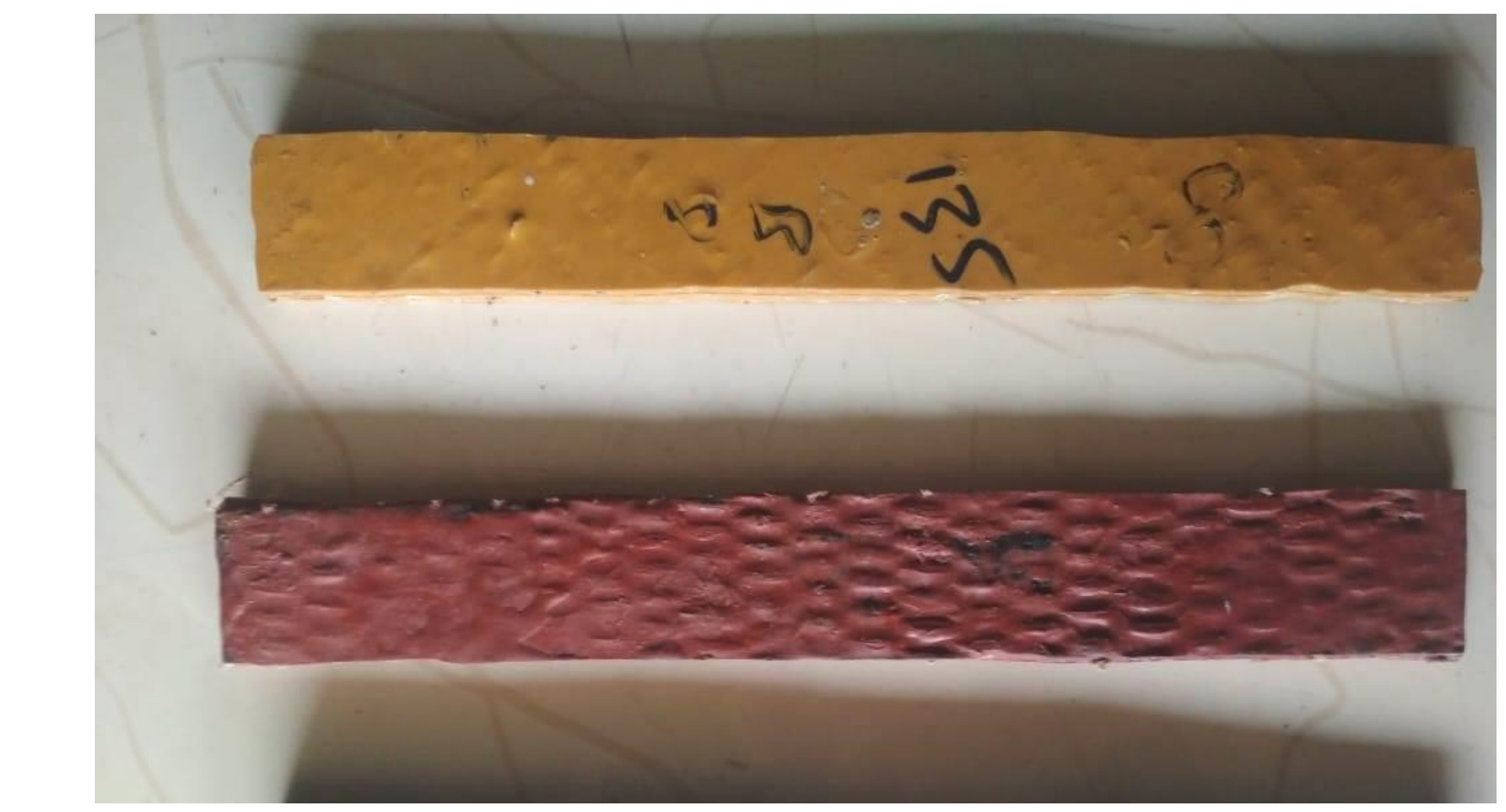

Fig.8 Sample of Flexural Test specimens

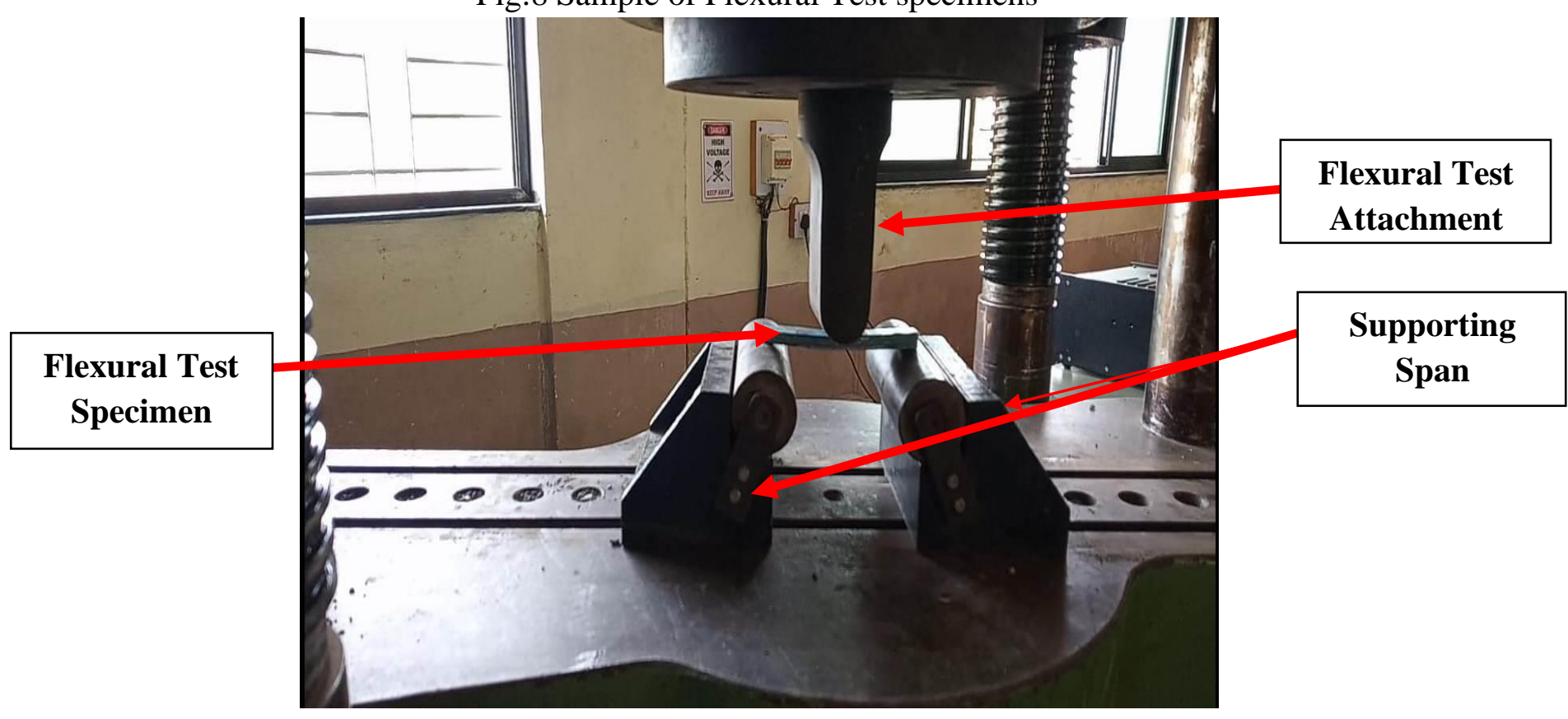

Fig.9 Experimental setup for 3-Point Flexural Test

\section{Results and Discussions:}

In all, sixteen experiments based on Taguchi $\mathrm{L}_{16}$ orthogonal array have been carried out (Refer Table- 6) and the results were obtained for Tensile strength (TS), Shear Strength (SS), and Flexural Strength (FS). The experimental results of mean and their associated S/N ratio values are presented in Table 7. The responses were analyzed by the ANOVA and Mean effect plot. The statistical software Minitab 16 was used to obtain these results of all experimental tests.

Table 7. S/N Ratios for TS, SS, and FS 


\begin{tabular}{ccccccc}
\hline $\begin{array}{c}\text { Expt. } \\
\text { No. }\end{array}$ & $\begin{array}{c}\text { Average } \\
\text { Tensile } \\
\text { Strength } \\
(\mathbf{M P a})\end{array}$ & $\begin{array}{c}\text { S/N } \\
\text { Ratio }\end{array}$ & $\begin{array}{c}\text { Average } \\
\text { Shear } \\
\text { Strength } \\
(\mathbf{M P a})\end{array}$ & $\begin{array}{c}\text { S/N } \\
\text { Ratio }\end{array}$ & $\begin{array}{c}\text { Average } \\
\text { Flexural } \\
\text { Strength } \\
(\mathbf{M P a})\end{array}$ & $\begin{array}{c}\text { S/N } \\
\text { Ratio }\end{array}$ \\
\hline 1 & 519.00 & 54.303 & 132.30 & 42.431 & 198.90 & 45.973 \\
\hline 2 & 230.56 & 47.256 & 244.53 & 47.767 & 350.26 & 50.888 \\
\hline 3 & 102.30 & 40.198 & 130.60 & 42.319 & 283.90 & 49.063 \\
\hline 4 & 225.50 & 47.063 & 199.40 & 45.995 & 289.25 & 49.225 \\
\hline 5 & 191.80 & 45.657 & 102.50 & 40.214 & 169.40 & 44.578 \\
\hline 6 & 121.60 & 41.699 & 163.50 & 44.270 & 210.20 & 46.453 \\
\hline 7 & 91.800 & 39.257 & 112.70 & 41.038 & 256.32 & 48.176 \\
\hline 8 & 100.20 & 40.017 & 156.23 & 43.875 & 150.10 & 43.528 \\
\hline 9 & 169.50 & 44.583 & 92.500 & 39.323 & 143.10 & 43.113 \\
\hline 10 & 120.30 & 41.605 & 156.23 & 43.875 & 189.20 & 45.538 \\
\hline 11 & 99.500 & 39.956 & 98.400 & 39.860 & 204.60 & 46.218 \\
\hline 12 & 123.60 & 41.840 & 128.30 & 42.165 & 201.50 & 46.086 \\
\hline 13 & 650.90 & 56.270 & 179.50 & 45.081 & 289.60 & 49.236 \\
\hline 14 & 495.68 & 53.904 & 251.23 & 48.001 & 342.02 & 50.681 \\
\hline 15 & 200.90 & 46.060 & 147.10 & 43.352 & 381.70 & 51.634 \\
\hline 16 & 422.60 & 52.519 & 198.30 & 45.946 & 365.70 & 51.262 \\
\hline
\end{tabular}

\subsection{Main effect plot and Analysis of Variance (ANOVA):}

The S/N ratios are used to measure responses of TS, SS, and FS to develop products and processes insensitive to the noise factor. Larger values of TS, SS, and FS indicate a good strength and higher mechanical properties of composite materials. As such, to calculate the $\mathrm{S} / \mathrm{N}$ ratios, "larger the better type" objective function was used for TS, SS, and FS.

The S/N ratio for the "larger the better type" of the objective function can be computed by using Eq. (1) [30].

$$
n=-10 \log _{10}\left(\frac{1}{R} \sum_{j=1}^{R}\left(1 / y_{j}^{2}\right)\right)-----
$$

Where $\mathrm{y}_{\mathrm{j}}$ is response value

At a 95\% confidence level, all the results were obtained for the 16 experimental tests and it was statistically analyzed using ANOVA and the effects of the selected design variables were evaluated. P-value establishes whether the design variables are significant or not at a particular confidence level. For a $95 \%$ confidence level, P-value must be less than 0.05 for the significant parameter. ANOVA identifies the effect of an individual variable on the mechanical properties of hybrid composites.

\subsubsection{Analysis of Tensile Strength:}

ANOVA Table 8 shows that the Stacking Angle and type of resin used are the most significant design variables. The percentage contributions of the stacking angle and the type of resins used are $30.21 \%$ and $55.23 \%$ respectively on the tensile strength of hybrid composite laminates and the rest of the design variables have a negligible effect on Tensile Strength. In Table 8, S is calculated in the response variable units and indicates how far from the fitted values the data 
values fall. The lower the $\mathrm{S}$ value, the better the answer is interpreted by the model. The higher the R-Sq value, the better the model fits the data. While the R-Sq value is $92.49 \%$ the statistical model will fit for the experimental data.

Table 8 ANOVA table for Tensile Strength

\begin{tabular}{ccccccccl}
\hline Source & DOF & Seq.SS & Adj.SS & Adj.MS & F Value & P Value & \%C & \\
\hline StSq & 3 & 29530 & 29530 & 9843 & 1.53 & 0.316 & 6.88 & \\
\hline StAn & 3 & 129642 & 129642 & 43214 & 6.70 & 0.033 & 30.21 & Significant \\
\hline Re & 3 & 236981 & 236981 & 78994 & 12.25 & 0.01 & 55.23 & Significant \\
\hline Th & 1 & 694 & 694 & 694 & 0.11 & 0.756 & 0.16 & \\
\hline Error & 5 & 32237 & 32237 & 6447 & & & 7.51 & \\
\hline Total & 15 & 429084 & & & & & & \\
\hline S=80.2956 & R-Sq=92.49\% & & & & & & \\
\hline
\end{tabular}

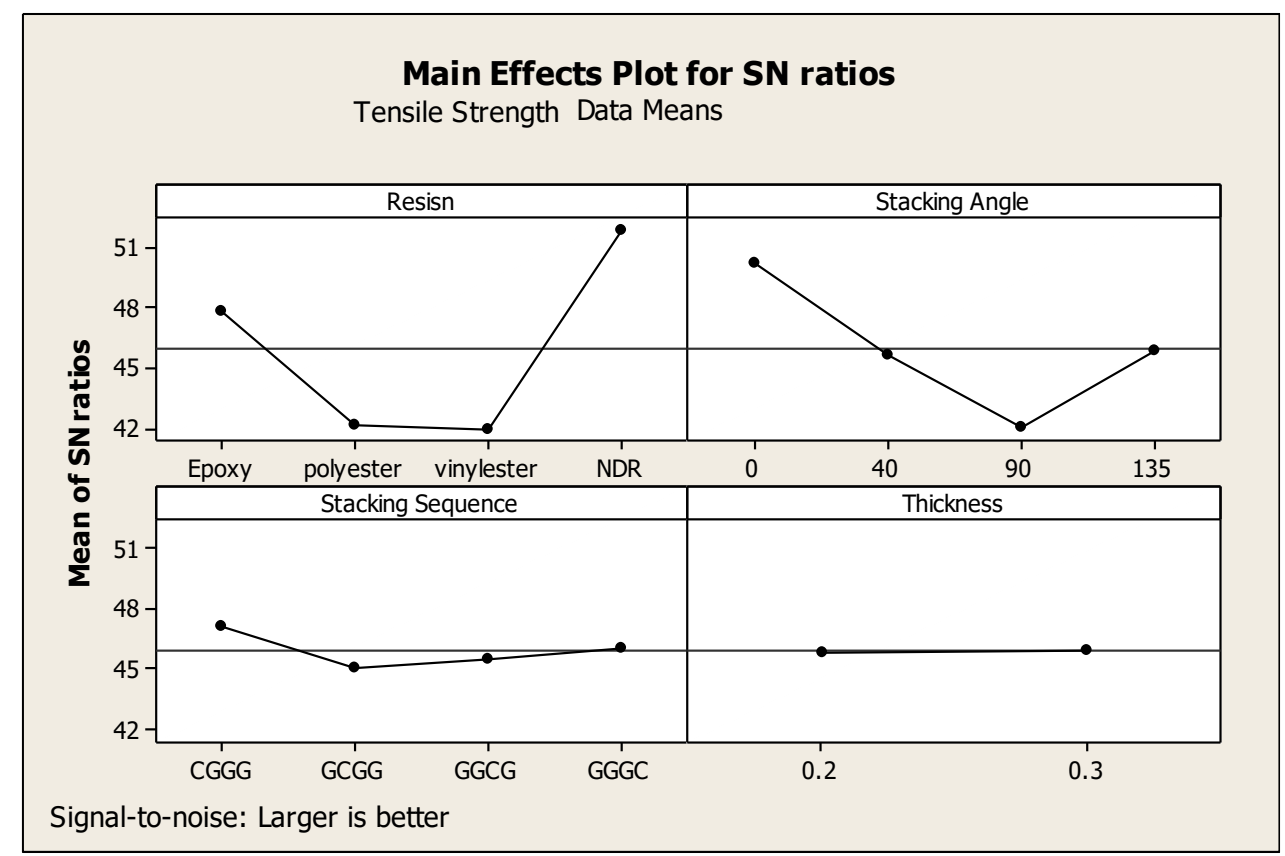

Fig.10 Effect of design variables on Tensile Strength (S/N data)

It is observed from the main effect plot for $\mathrm{S} / \mathrm{N}$ ratio (Fig.10), that the effect of resin and stacking angle plays an important role in the tensile strength of hybrid composite laminates whereas the effect of stacking sequence and thickness is negligible. If the line is horizontal (parallel to the $\mathrm{x}$ axis), then the main effect is not. Each factor level has the same effect on the response, and the mean of response is the same across all factor levels. If the line isn't horizontal then the main effect is there. Different levels of the factor affect the response differently. In fig. 10, the lines for stacking sequence and laminate thickness are horizontal and hence there was no main effect of these design variables. For types of resins and stacking angles, the lines are not horizontal and hence these are the two most significant design variables.

\subsubsection{Analysis of Shear Strength:}

ANOVA Table 9 indicates that the Stacking Angle and type of resin used are the most significant design variables. The percentage contributions of the stacking angle and the type of resin used are $53.27 \%$ and $43.32 \%$ respectively on the shear strength of hybrid composite laminates and the 
rest of the design variables have a negligible effect on shear strength. It has been observed that in the case of tensile strength, the type of resin used is the most significant factor with $55.23 \%$ (refer table 8) whereas for shear strength the stacking angle is the most significant factor with 53.27\%. In this ANOVA, S value is lower i.e.11.69 and the R-Sq value is higher i.e. 96.84\%. Hence statistical model can better describe the response as well as it will be fit for the experimental data.

Table 9.ANOVA table for Shear Strength

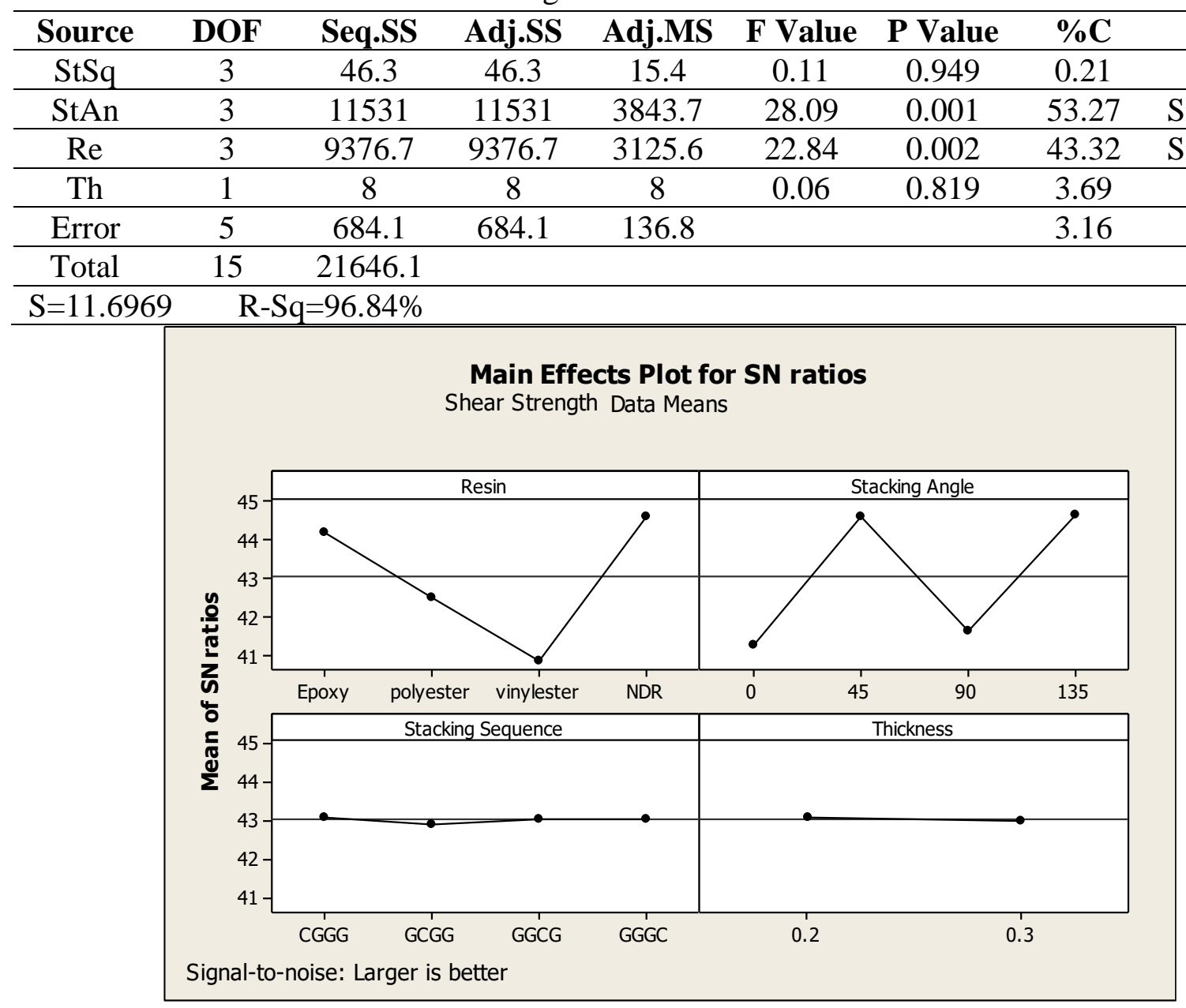

Fig.11 Effect of design variables on Shear Strength (S/N data)

Fig. 11 shows the influence of the stacking angle is very vital on the shear strength of the hybrid composite laminates. As like tensile strength, the effect of stacking sequence and thickness is insignificant on shear strength. Epoxy and NDR gives approximately equal effect on shear strength.

\subsubsection{Analysis of Flexural Strength:}

ANOVA Table 10 revealed that on flexural strength the resin and stacking angle both are the significant parameters. It has been detected that the effect of resin is highly significant with a $75.55 \%$ contribution to the flexural strength of the hybrid composite laminate. Fig. 12 shows the effect of all design variables on flexural strength. NDR gives a higher flexural strength as compared with other resins. The influence of stacking sequence and thickness is not significant on the flexural strength of the hybrid composite laminate. In table 10 , the $\mathrm{S}$ value is 13.49 which 
is lower and the R-Sq value is $98.62 \%$ which is very higher. Hence statistical model can better describe the response as well as it will be fit for the experimental data.

Table 10.ANOVA table for Flexural Strength

\begin{tabular}{ccccccccl}
\hline Source & DOF & Seq.SS & Adj.SS & Adj.MS & F Value & P Value & \% C & \\
\hline StSq & 3 & 1589.2 & 1589.2 & 529.7 & 2.91 & 0.14 & 2.40 & \\
\hline StAn & 3 & 13670.9 & 13670.9 & 4557.0 & 25.03 & 0.002 & 20.67 & Significant \\
\hline Re & 3 & 49980.2 & 49980.2 & 16660.1 & 91.51 & 0.00 & 75.55 & Significant \\
\hline Th & 1 & 1.4 & 1.4 & 1.4 & 0.01 & 0.933 & 0.0002 & \\
\hline Error & 5 & 910.3 & 910.3 & 182.1 & & & 1.37 & \\
\hline Total & 15 & 66152.1 & & & & & & \\
\hline S=13.4927 & R-Sq=98.62\% & & & & & & \\
\hline
\end{tabular}

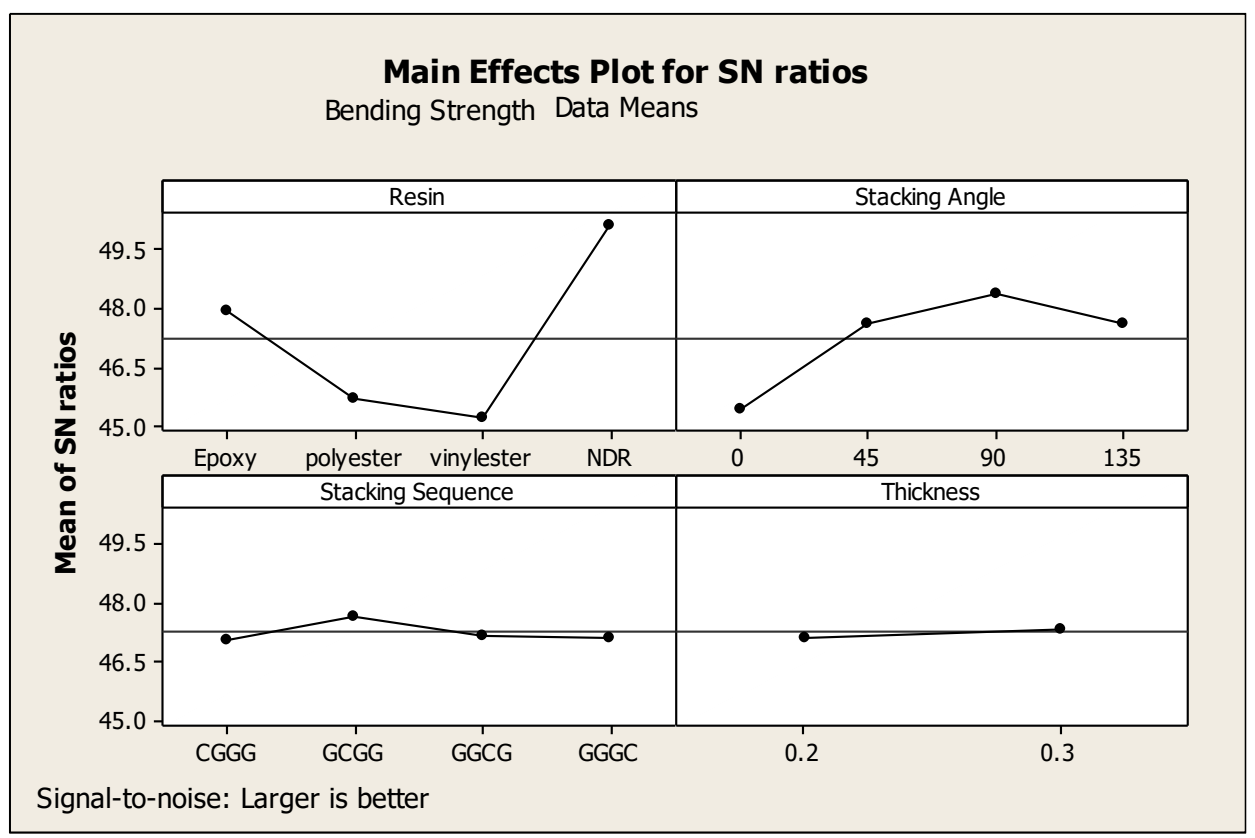

Fig.12 Effect of design variables on flexural strength(S/N data)

\section{Multi-objective optimization using Grey Relation Analysis:}

The mechanical properties of hybrid composite laminates are dependent on a number of parameters. Thus the task of multi-objective optimization of design variables is more intricate than the optimization of a single design variable. From earlier investigations, it is observed that the GRA method has the capacity to tackle the complexity in multi-objective optimization [3031]. Some researchers [40, 41] have used both the GRA approach and the Firefly algorithm (FA) for optimization of process parameters for Laser Beam Cutting. They identified more improvement in optimization in combination with the Firefly algorithm than the GRA. Varun and Venkaiah [42] used the hybrid optimization method of FA with GRA to overcome the limitation of FA by providing the grey relational grading to the parameters. Some researcher shows GRA was the most effective method to carry out the optimization of multivariable over the other methods $[33,34]$. As all algorithms have some limitations mentioned in the No Launch Theorem. [43] But GRA proves more tenacity in multi-objective optimization for nonhomogeneous materials, and this technique has been the most effective method to tackle the 
nonlinear multiple dimensional problems. So, it has been decided to adopt the GRA approach to carry out the optimization of design variables. In this method, the multi-performance parameters have been converted into a single grey relational grade.

GRA has been carried out in the following step.

- Normalization of each performance parameter

- Obtaining the deviation sequence

- Determining the gray relational coefficient (GRC) and gray relational grade(GRG)

- Excerpting the optimal level variables and ANOVA of GRG

- Validation Test

Step I: Normalization of each performance parameter

The first step of GRA consists of normalization of the experimental data i.e. S/N ratio in order to convert the original sequence to a corresponding sequence (i.e. dimensionless data sequence). Measured values of response characteristics are normalized between zero to one. The TS, SS, and FS are the larger the better type characteristics. Hence, its original sequence can be normalized by using Eq. (2) and it has been shown in Table 11.

$$
x_{i}^{*}(k)=\frac{x_{i}^{0}(k)-\min x_{i}^{0}(k)}{\operatorname{maxx} x_{i}^{0}(k)-\min x_{i}^{0}(k)} \quad---(2)
$$

Where, $\mathrm{Xi}^{0}(\mathrm{k})$ represents an original sequence, $\mathrm{Xi}^{*}(\mathrm{k})$ represents comparability sequence, $\mathrm{i}=1,2,3, \ldots \mathrm{m}[\mathrm{m}$ is the total no. experiment performed],

$\mathrm{k}=1,2,3, \ldots \mathrm{n} \quad[\mathrm{n}$ is the number of parameter considered], In present work $\mathrm{m}=16$ and $\mathrm{n}=3$.

Table 11.Normalized S/N ratio for TS, SS, and FS

\begin{tabular}{cccc}
\hline Expt. No. & Tensile Strength (TS) & Shear Strength(SS) & Flexural Strength(FS) \\
\hline Ref. sequence & 1.0000 & 1.0000 & 1.0000 \\
\hline 1 & 0.884 & 0.358 & 0.336 \\
\hline 2 & 0.470 & 0.973 & 0.912 \\
\hline 3 & 0.055 & 0.345 & 0.698 \\
\hline 4 & 0.459 & 0.769 & 0.717 \\
\hline 5 & 0.376 & 0.103 & 0.172 \\
\hline 6 & 0.144 & 0.570 & 0.392 \\
\hline 7 & 0.000 & 0.198 & 0.594 \\
\hline 8 & 0.045 & 0.525 & 0.049 \\
\hline 9 & 0.313 & 0.000 & 0.000 \\
\hline 10 & 0.138 & 0.525 & 0.285 \\
\hline 11 & 0.041 & 0.062 & 0.364 \\
\hline 12 & 0.152 & 0.327 & 0.349 \\
\hline 13 & 1.000 & 0.663 & 0.718 \\
\hline 14 & 0.861 & 1.000 & 0.888 \\
\hline 15 & 0.400 & 0.464 & 1.000 \\
\hline 16 & 0.779 & 0.763 & 0.956 \\
\hline
\end{tabular}

Step II: Obtaining Deviation sequence: 
After normalization, it is essential to calculate deviation sequence $\boldsymbol{\Delta}_{\mathbf{o i}} \mathbf{k}$, which is the complete difference between the reference sequence $\mathrm{x}_{0} *(\mathrm{k})$ and the comparability sequence $\mathrm{x}_{\mathrm{i}}^{*}(\mathrm{k})$. The deviation sequence is presented in Table 12

Note: Reference sequence $\mathrm{x}_{0} *(\mathrm{k})=1$

$$
\boldsymbol{\Delta}_{o i} k=\left|x_{0}^{*}(k)-x_{i}^{*}(k)\right| \quad---(3)
$$

Table 12.Deviation Sequence for TS, SS, and FS

\begin{tabular}{|c|c|c|c|c|c|c|c|c|}
\hline \multicolumn{4}{|c|}{ Deviation } & \multicolumn{5}{|c|}{ GRC and GRG } \\
\hline $\begin{array}{l}\text { Deviation } \\
\text { Sequence }\end{array}$ & $\begin{array}{l}\Delta_{01} \\
\text { TS }\end{array}$ & $\begin{array}{l}\Delta_{01} \\
\text { SS }\end{array}$ & $\begin{array}{l}\Delta_{01} \\
\text { FS }\end{array}$ & TS & SS & FS & $\begin{array}{l}\text { Grade } \\
\text { Value }\end{array}$ & Rank \\
\hline No. $1, i=1$ & 0.116 & 0.642 & 0.664 & 0.812 & 0.438 & 0.429 & 0.560 & 7 \\
\hline No. $2, i=2$ & 0.530 & 0.027 & 0.088 & 0.486 & 0.949 & 0.851 & 0.762 & 3 \\
\hline No. $3, \mathrm{i}=3$ & 0.945 & 0.655 & 0.302 & 0.346 & 0.433 & 0.624 & 0.468 & 8 \\
\hline No. $4, \mathrm{i}=4$ & 0.541 & 0.231 & 0.283 & 0.480 & 0.684 & 0.639 & 0.601 & 6 \\
\hline No. $5, \mathrm{i}=5$ & 0.624 & 0.897 & 0.828 & 0.445 & 0.358 & 0.376 & 0.393 & 14 \\
\hline No. $6, \mathrm{i}=6$ & 0.856 & 0.430 & 0.608 & 0.369 & 0.538 & 0.451 & 0.452 & 9 \\
\hline No.7, $\mathrm{i}=7$ & 1.000 & 0.802 & 0.406 & 0.333 & 0.384 & 0.552 & 0.423 & 11 \\
\hline No. $8, \mathrm{i}=8$ & 0.955 & 0.475 & 0.951 & 0.344 & 0.513 & 0.345 & 0.400 & 13 \\
\hline No.9, $\mathrm{i}=9$ & 0.687 & 1.000 & 1.000 & 0.421 & 0.333 & 0.333 & 0.363 & 16 \\
\hline No.10, $\mathrm{i}=10$ & 0.862 & 0.475 & 0.715 & 0.367 & 0.513 & 0.411 & 0.430 & 10 \\
\hline No.11, i=11 & 0.959 & 0.938 & 0.636 & 0.343 & 0.348 & 0.440 & 0.377 & 15 \\
\hline No.12, $\mathrm{i}=12$ & 0.848 & 0.673 & 0.651 & 0.371 & 0.426 & 0.434 & 0.411 & 12 \\
\hline No.13, $\mathrm{i}=13$ & 0.000 & 0.337 & 0.282 & 1.000 & 0.598 & 0.640 & 0.746 & 4 \\
\hline No. $14, \mathrm{i}=14$ & 0.139 & 0.000 & 0.112 & 0.782 & 1.000 & 0.817 & 0.866 & 1 \\
\hline No. $15, \mathrm{i}=15$ & 0.600 & 0.536 & 0.000 & 0.454 & 0.483 & 1.000 & 0.646 & 5 \\
\hline No. $16, i=16$ & 0.221 & 0.237 & 0.044 & 0.694 & 0.679 & 0.920 & 0.764 & 2 \\
\hline
\end{tabular}

In above table 12, the ranks were given based on Grade values in ascending to descending order. According to OA, experimental trial no.14 gives less deviation as the grade value was higher than the other trials. Whereas, for trial no. 9 the grade value was lower as the deviation was higher.

Step III: Determining GRC and GRG:

Grey relational coefficient denotes the correlation between the best and actual experimental results. The GRC can be expressed by Eq. (4)

$$
\gamma\left(x_{0}{ }^{*}(k), x_{i}{ }^{*}(k)\right)=\frac{\Delta_{\min }+\zeta . \Delta_{\max }}{\Delta_{0 i}(k)+\zeta . \Delta_{\max }} \quad---(4)
$$

and, $0<\gamma\left(x_{0}{ }^{*}(k), x_{i}^{*}(k)\right) \leq 1$

Where,

$\Delta_{0 \mathrm{i}}(\mathrm{k})$ is the deviation sequence of the reference sequence $\mathrm{x}_{0} *(\mathrm{k})$ and comparability sequence $\mathrm{xi}^{*}(\mathrm{k})$ (Refer Eq. 3).

And, $\quad \Delta_{\max }=\max \left|\mathbf{x}_{\mathbf{0}}^{*}(\mathbf{k})-\mathbf{x}_{\mathbf{i}}^{*}(\mathbf{k})\right|=1$

$\Delta_{\min }=\min \left|\mathbf{x}_{\mathbf{0}}^{*}(\mathbf{k})-\mathbf{x}_{\mathbf{i}}^{*}(\mathbf{k})\right|=0$

$\zeta=$ Distinguishing coefficient, $\zeta \in(0,1)$ for present study, $\zeta$ was set as 0.5 based. 
The GRG assist to detect the best set of design variables with which validation tests can be carried out. i.e. higher GRG exhibits the concerned parameter combination is very nearer to the optimum value. An average sum of GRG can be obtained from Eq. (5).

$$
\gamma\left(x_{0}{ }^{*}, x_{i}^{*}\right)=\frac{1}{m} \sum_{i=1}^{m} \gamma\left(x_{0}^{*}(k), x_{i}^{*}(k)\right)
$$

Where,

$$
\begin{aligned}
& \boldsymbol{\gamma}\left(\mathbf{x}_{\mathbf{0}}{ }^{*}, \mathbf{x}_{\mathbf{i}}{ }^{*}\right) \text { is the GRG for } \mathrm{m} \text { experiment, } \mathrm{m}=1,2,3, . . \mathrm{n} \\
& \mathrm{n}=\text { no. of performance characteristics }=3
\end{aligned}
$$

\section{Step IV: Excerpting the optimal level variables and ANOVA of GRG}

Table 12 presents the grey relational grade for all comparability sequence, larger the grey relational grade, better the corresponding multi-objective characteristics, the value of GRG for experiment No. 14 is more which indicates that the design variables "Setting of experiment A3B2C4D2" offers best multiple design variables among the sixteen experiments.

The response table established from the Taguchi method for the S/N ratios of the grey relational grade is given in Table 13. The influence of each level of design variables on grey relational grade can be determined from the table. From the response table for GRG; the best set of combinations of the design variable is A2B2C4D1. The ranks have been decided from the maximum value of the design variable. The highest maximum value in Table 13 is 0.756 for the resin. Hence the resin is the most significant design variable and hence given rank 1. Similarly, table 13 indicates the lowest maximum value design variable is the laminate thickness and hence given the rank 4. From table 14, these sequence of these ranks has been justified from the percentage contribution of the design variables.

Table 13.Response table for the grey relational grade (GRG)

\begin{tabular}{ccccc}
\hline Level & StSq & StAn & Re & Th \\
\hline 1 & 0.517 & 0.515 & 0.597 & 0.543 \\
\hline 2 & 0.574 & 0.628 & 0.417 & 0.539 \\
\hline 3 & 0.511 & 0.478 & 0.395 & - \\
\hline 4 & 0.563 & 0.544 & 0.756 & - \\
\hline Max & 0.574 & 0.628 & 0.756 & 0.543 \\
\hline Min & 0.511 & 0.478 & 0.395 & 0.539 \\
\hline Delta & 0.063 & 0.149 & 0.360 & 0.004 \\
\hline Rank & 3 & 2 & 1 & 4 \\
\hline
\end{tabular}

The total mean value of GRG is 0.541

\subsection{ANOVA of GRG:}

The calculated GRG was considered as a single response for the designed experiment and analysis of variance was carried out to determine the design variables which have the most significant effect on multi-objective response. ANOVA for GRG is presented in Table 14. From the table, it can be seen that resin is the most significant design variable for the optimum multiresponse. All other design variables have a minor effect on the mechanical properties of hybrid composite laminates. In ANOVA of GRG, S value is very lower and the R-Sq value is extremely 
higher. Hence the statistical model can interpret the proper responses. Also, the model will perfectly fit with the experimental data.

Table 14.ANOVA for $\mathrm{S} / \mathrm{N}$ ratios (GRG)

\begin{tabular}{lllllcccl}
\hline Source & DOF & Seq.SS & Adj.SS & Adj.MS & F & P & \% C & \\
\hline StSq & 3 & 0.002032 & 0.002032 & 0.000677 & 0.14 & 0.932 & 0.4860 & \\
\hline StAn & 3 & 0.04848 & 0.04848 & 0.01616 & 3.34 & 0.114 & 11.5969 & \\
\hline $\operatorname{Re}$ & 3 & 0.34325 & 0.34325 & 0.11442 & 23.62 & 0.002 & 82.1093 & Significant \\
\hline Th & 1 & 0.00007 & 0.00007 & 0.00007 & 0.01 & 0.908 & 0.0001 & \\
\hline Error & 5 & 0.02422 & 0.02422 & 0.004844 & & & 5.8958 & \\
\hline Total & 15 & 0.41804 & & & & & & \\
\hline S $=0.06960$ & R-Sq=94.2\% & & & & & & \\
\hline
\end{tabular}

The main effect plot for GRG is as shown in Fig. 13. The maximum GRG values were recognized at NDR resign, stacking angle $45^{\circ}$, stacking sequence G/C/G/G and thickness 0.2 $\mathrm{cm}$. Hence the combination of these design variables gives the optimal result for multi-response.

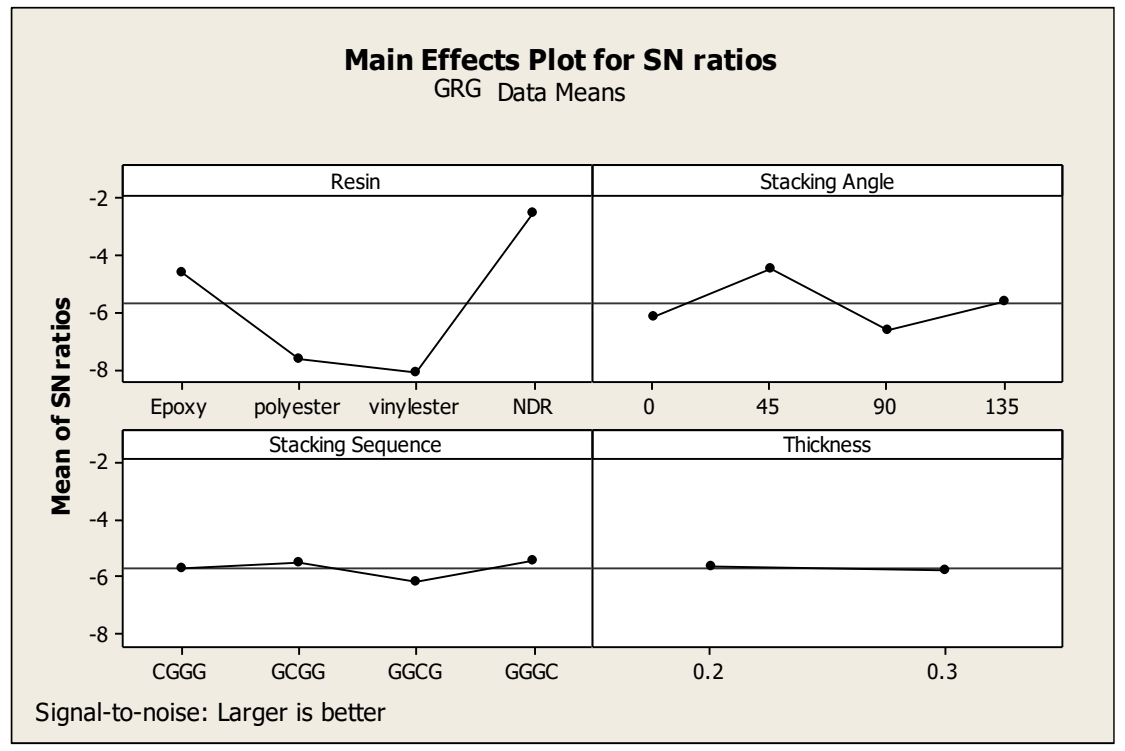

Fig.13 Main effect plot for GRG (S/N data)

Step V: Validation (Confirmation) Test

Subsequently evaluating the optimal parameters set, the next step was to determine the improvement of quality characteristics. The optimal Grey Relational grade $\boldsymbol{\eta}_{\text {opt }}$ is determined using Equation 6.

$\eta_{\text {opt }}=\overline{\mathbf{T}}+\left(\overline{\mathbf{A}}_{(1 / 2 / 3 / 4)}-\overline{\mathbf{T}}\right)+\left(\overline{\mathbf{B}}_{(1 / 2 / 3 / 4)}-\overline{\mathbf{T}}\right)+\left(\overline{\mathbf{C}}_{(1 / 2 / 3 / 4)}-\overline{\mathbf{T}}\right)+\left(\overline{\mathbf{D}}_{(1 / 2)}-\overline{\mathbf{T}}\right)--(\mathbf{6})$

Where,

$\overline{\mathbf{T}}=$ Total mean of the response

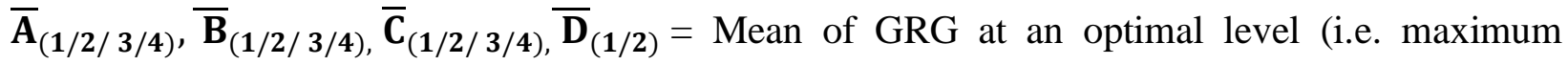
values of response at the first or second or third level of parameters $\mathrm{A}, \mathrm{B}, \mathrm{C}$, and D respectively) In the present work, $\overline{\mathbf{T}}=0.541$ 
$\eta_{\text {opt }}=0.541+(0.574-0.541)+(0.628-0.541)+(0.756-0.541)+(0.543-0.541)$

$\eta_{\text {opt }}=0.878$

Finally, a validation test was carried out using the optimum combination of the parameter (A2B2C4D1). Table 15 shows the comparison of predicted values of GRG with the initial setting as well as the experimental results of the optimal test parameter. The improvement in GRG from initial parameter combination A3B2C4D2 $\left(\mathrm{G} / \mathrm{G} / \mathrm{C} / \mathrm{G}, 45^{\circ}, \mathrm{NDR}, 0.3 \mathrm{~cm}\right)$ to the optimal parameter combination A2B2C4D1 (G/C/G/G, 45 , NDR, $0.2 \mathrm{~cm}$ ) is 0.012 , which is $1.366 \%$ of initial setting. This improvement was observed because the use of NDR has increased the bonding strength of fibers. The experimental values for Tensile Strength, Shear Strength, and Flexural Strength are shown in Table 16.

Table 15.Predicted and Experimental results

\begin{tabular}{lccc}
\hline Design Variables & Initial Setting & Predicted value & Experimental Value \\
\hline Optimal variables & A3B2C4D2 & A2B2C4D1 & A2B2C4D1 \\
\hline StSq & GGCG & GCGG & GCGG \\
\hline StAn & 45 & 45 & 45 \\
\hline Re & NDR & NDR & NDR \\
\hline Th & 0.3 & 0.2 & 0.2 \\
\hline Grey Relational Grade & 0.866 & 0.878 & 0.875 \\
\hline Improvement of the GRG $=1.366 \%$ & & \\
\hline
\end{tabular}

Table 16 Experimental test values for TS, SS and FS

\begin{tabular}{lccc}
\hline & TS & SS & FS \\
\hline $\begin{array}{l}\text { Experimental Value- } \\
\text { Trail No.17 }(\mathrm{MPa})\end{array}$ & 505.23 & 248.96 & 349.56 \\
\hline
\end{tabular}

7. Scanning Electron Microscope (SEM) analysis:
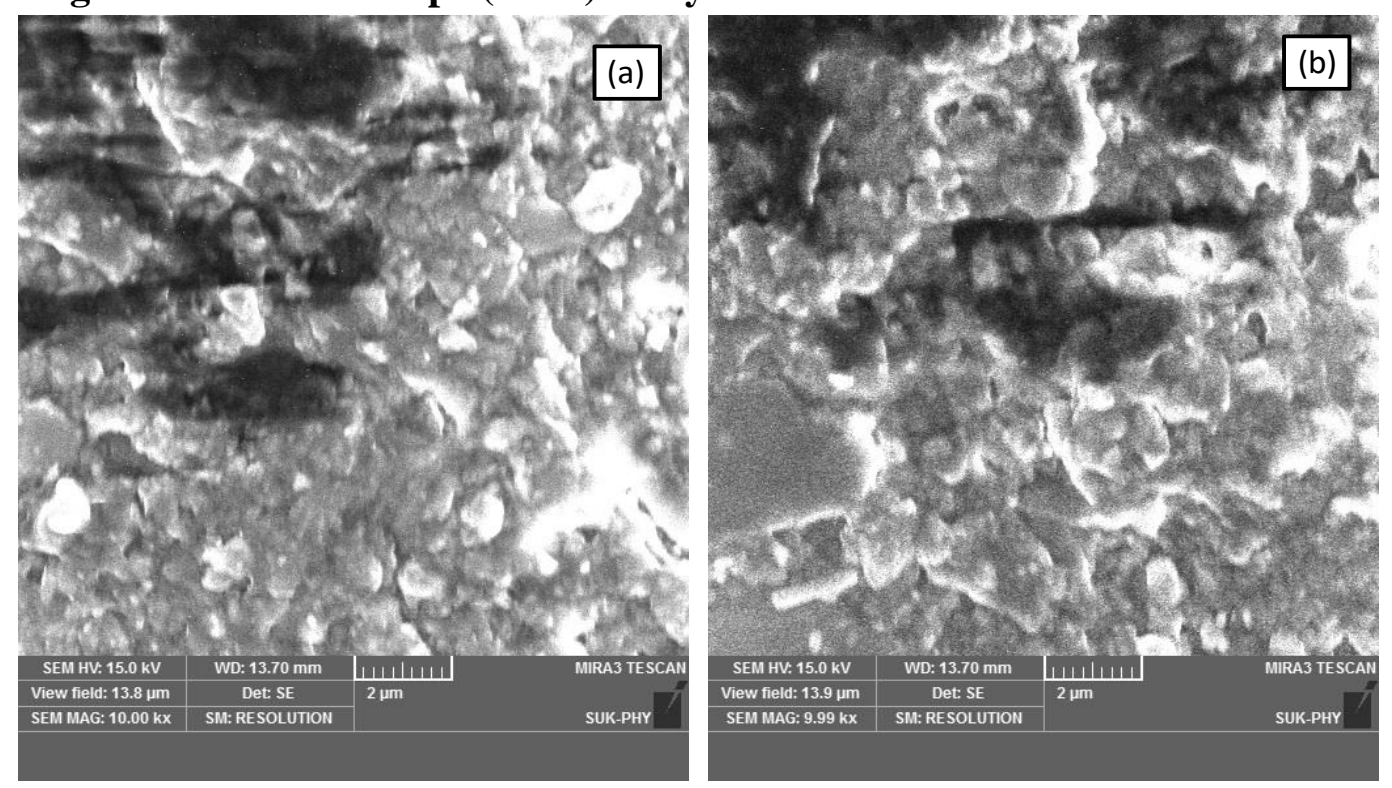

Fig.14 FESEM Images of (a) Initial setting sample (b) Validation test sample 
The surface morphology of the Initial setting sample and Validation test sample were investigated using a Mira-3, Tescan, Brno-Czech Republic, Field Emission Scanning Electron Microscope (FE-SEM). Fig. 14 shows the FESEM images of (a) Initial setting sample (b) Validation Test sample recorded with $10 \mathrm{kx}$ magnification. In FESEM images the grain-like morphology was observed in the samples. The crack-free and densely packed structures were observed in samples. The grain size of the Initial setting sample was about $2 \mu \mathrm{m}$ whereas for the Validation Test sample it was observed that $1.5 \mu \mathrm{m}$. In Fig. (b), the well-interconnected grains were observed than Fig. 14(a). Hence the GRG value was increased by $1.366 \%$.

\section{Conclusions:}

In this research work, the effect of design variables such as stacking sequence, stacking angle, types of resins (including NDR) and thickness on mechanical properties (tensile strength, shear strength, and flexural strength) of hybrid composite laminates has been experimentally investigated. The Taguchi method consolidated with GRA was used to optimize to identify design variable setting for maximum tensile, shear, and flexural strengths of hybrid composite laminates. As compared with the results obtained [30] by the GRA method for metal composites, in this research the more accurate and robust results were obtained.

Based on the results of experimental investigation and optimization, the following conclusions are drawn

1) From the experimental analysis and optimization study, it was seen that the NDR gives excellent bonding strength of fibers resulting in enhanced mechanical properties of hybrid composite laminates variable

2) The ANOVA at $95 \%$ confidence level illustrates that the resin is the most significant variable for Tensile and Flexural strength with $55.23 \%$ and $75.55 \%$ contribution respectively. Whereas the stacking angle is the most significant variable for shear strength with a contribution of $53.27 \%$.

3) The results of ANOVA interpret that the maximum contribution to GRG was by resin $(82.11 \%)$ and pursue in abating order by stacking angle $(11.60 \%)$, stacking sequence $(0.486 \%)$ and laminate thickness $(0.0001 \%)$. Hence resin was identically the most significant design variable. The stacking angle, stacking sequence, and thickness were the nonsignificant design variables.

4) The validation test indicated that there is an enhancement in the overall GRG at an optimal level of design variables by $1.366 \%$ Therefore, using the GRA approach of analysis; design variables have been successfully optimized to achieve enhanced mechanical properties of hybrid composite laminates.

\section{References:}

[1] Thanomsilp C, Hogg PJ. "Penetration impact resistance of hybrid composites on commingled yarn fabrics". Compos Sci Technol 2003;63:467-482. 
[2] Wong W, Horsfall I, Champion SM, Watson CH. "The effect of matrix type on the ballistic and mechanical performance of E-glass composite armour". In: 19th international symposium of ballistics, 7-11 May 2001, Interlaken, Switzerland.

[3] Muhi RJ, Najim F, De Moura MFSF. "The effect of hybridization on the GFRP behavior under the high-velocity impact". Composites B 2009;40:783-803.

[4] Huda MS, Drazel LT, Mohanty AK, Misra M. "The effect of silane treatment- and untreatedtalc on the mechanical and physio-mechanical properties of poly(lactic acid)/newspaper fibers/talc hybrid composites". Composites B 2007;38:367-379.

[5] Cheon SS, Lim TS, Lee DG. "Impact energy absorption characteristics of glass fiber hybrid composites". Compos Struct 1999;46:267-278.

[6] Saha N, Banerjee AN, Mitra BC. "Tensile behavior of unidirectional polyethylene-glass fibers/PMMA hybrid composite laminates". Polymer 1996;37(4):699-701.

[7] Rout J, Misra M, Tripathy SS, Nayak SK, Mohanty AK. "The influence of fiber treatment on the performance of coir-polyester composites". Compos Sci Technol 2001;61:1303-1310.

[8] Singh S, Mohanty AK, Misra M. "Hybrid bio-composite from talc and wood fiber and bioplastic: fabrication and characterization". Composites A 2010;41:304-312.

[9] Leong YW, Abu Bakar MB, Mohd Ishak ZA, Arrifin A. "Characterization of talc/calcium carbonate filled polypropylene hybrid composites weathered in a natural environment". Polym Degrad Stab 2004;83:411-422.

[10] Ramakrishna S, Mayer J, Wintermantel E, Leong KW. "Biomedical applications of polymer-composite materials: a review". Compos Sci Technol 2001;61:1189-1224.

[11] Hosseinzadeh R, Shokrieh MM, Lessad L. "Damage behavior of fiber-reinforced composite plates subjected to drop weight impacts". Compos Sci Technol 2006;66:61-68.

[12] Morye SS, Hine PJ, Duckett RA, Carr DJ, Ward IM. "Modeling the effect of the energy absorption by polymer composites upon ballistic impact". Compos Sci Technol 2000;60:26312642.

[13]Dong C, Davies IJ. "Flexural properties of glass and carbon fiber reinforced epoxy hybrid composites". Procee Inst Mech Eng, Part L: J Mater Design Appl 2013;227(4):308-317.

[14] Dong C, Davies IJ. "Flexural properties of E glass and TR50S carbon fiber reinforced epoxy hybrid composites". J Materials Eng Perform 2013;22(1):41-49.

[15] Dong C, Duong J, Davies IJ. "Flexural properties of S-2 glass and TR30S carbon fiberreinforced epoxy hybrid composites". Polym Compos 2012;33(5):773-781.

[16] Dong C, Ranaweera-Jayawardena HA, Davies IJ. "Flexural properties of hybrid composites reinforced by S-2 glass and T700S carbon fibres". Compos Part B: Eng 2012;43(2):573-581.

[17] Dong C, Davies IJ. "Optimal design for the flexural behavior of glass and carbon fibre reinforced polymer hybrid composites". Mater Design 2012;37:450-457.

[18]Dong C, Davies IJ. "Flexural and tensile strengths of unidirectional hybrid epoxy composites reinforced by S-2 glass and T700S carbon fibres". Mater Design 2014;54:955-966.

[19] Dong C, Davies IJ. "Flexural and tensile moduli of unidirectional hybrid epoxy composites reinforced by S-2 glass and T700S carbon fibres". Mater Design 2014;54:893-899.

[20] Caroline G. de Oliveira, Frederico M. Margemb, Sergio N. Monteiroc, Felipe Perissé Duarte Lopesc "Comparison between tensile behavior of epoxy and polyester matrix composites reinforced with eucalyptus fibers" jmr\&t 2017; 6(4):406-410 
[21] Natalia de Oliveira Roque Maciel, Jordana Barreto Ferreira, Janaína da Silva Vieira, Carolina Gomes Dias Ribeiro, Felipe Perissé Duarte Lopes, Frederico Muylaert Margem, Sergio Neves Monteiro, Carlos Maurício Fontes Vieira, Luís Carlos da Silva "Comparative tensile strength analysis between epoxy composites reinforced with curaua fiber and glass fiber" jmr\&t . 2018 ; 7(4):561-565.

[22] Dipak Kumar Jesthi, Ramesh Kumar Nayak "Improvement of mechanical properties of hybrid composite through interply rearrangement of glass and carbon woven fabrics for marine applications" Composites Part B. Volume 168, 1 July 2019, Pages 467-475.

[23] Konrad Dadej, Jaroslaw Bienias, Barbara Surowska "On the effect of glass and carbon fiber hybridization in fiber metal laminates: Analytical, numerical and experimental investigation Composite Structures" https://doi.org/10.1016/j.compstruct.2019.03.05.

[24] I.D.G. Ary Subagia, Yonjig Kim, Leonard D. Tijing, Cheol Sang Kim, Ho Kyong Shon "Effect of stacking sequence on the flexural properties of hybrid composites reinforced with carbon and basalt fibers Composites": Part B 58 (2014) 251-258.

[25] Lokman Gemi "Investigation of the effect of stacking sequence on low velocity impact response and damage formation in hybrid composite pipes under internal pressure. A comparative study" Composites Part B 153 (2018) 217-232.

[26] Mehdi Kalantari, Chensong Dong and Ian J. Davies "Multi-objective robust optimization of unidirectional carbon/glass fibre reinforced hybrid composites under flexural loading Composite Structures" Volume 138, 15 March 2016, Pages 264-275

[27] Mehdi Kalantari, Chensong Dong, Ian J. Davies "Multi-objective robust optimization of multi-directional carbon/glass fiber-reinforced hybrid composites with manufacture related uncertainties under flexural loading Composite Structures" Volume 182, 15 December 2017, Pages 132-142.

[28] M.S. Senthil Kumar, N. Mohana Sundara Raju, P.S. Sampath, U. Vivek "Tribological Analysis of Nano Clay/ Epoxy/ Glass Fiber by using Taguchi's Technique" Materials and Design Volume 70, 5 April 2015, Pages 1-9.

[29] Shyam Lal, Sudhir Kumar, Zahid A Khan and Arshad N Siddiquee "Multi-response optimization of wire electrical discharge machining process parameters for A17075/A12O3/SiC hybrid composite using Taguchi-based grey relational analysis" Proc IMechE Part B: J Engineering Manufacture 1-9.

[30] A.M. Takale, N.K. Chougule "Multi-objective optimization of WEDM process parameters of Ti49.4-Ni50.6 shape memory alloy for orthopedic implant application archives of material science and engineering" Volume 93 Issue 1 September 2018 Pages 12-31.

[31] Faramarz Ashenai Ghasemi a, Ismail Ghasemi b, Saman Menbari a, Mohsen Ayaz c, Alireza Ashori "Optimization of mechanical properties of polypropylene/talc/ graphene composites using response surface methodology" Polymer Testing 53 (2016) 283-292.

[32] P.K. Mallick, "Fiber-Reinforced Composite Materials", ISBN 13:978-0-8493-4205-9, Third Edition, USA.

[33]Amirmahdi Malek, Sadoullah Ebrahimnejad, and Reza Tavakkoli-Moghaddam “An Improved Hybrid Grey Relational Analysis Approach for Green Resilient Supply Chain Network Assessment" Sustainability, Vol. 9, 1-28. 
[34] Hsin-Hung Wu "A Comparative Study of Using Grey Relational Analysis in Multiple Attribute Decision Making Problems" Quality Engineering, Vol. 15 issue 2, 209-217.

[35]Jing S.,Ali, D. , Guoxing, L., Dong, R., Yang, L.V., "Tensile failure of fibre-metallaminates made of titanium and carbon-fibre/epoxy laminates", Materials and Design, (2019) Vol. 183, pp.108-139.

[36]Sambran F.B., Meuchelboeck, J., Kazemi-Khasragh, E., Eslami-Farsani, R., Arbab Chirani, S. "The effect of surface modified nanoclay on the interfacial and mechanical properties of basalt fiber metal laminates" Thin-Walled Structures (2019), Vol. 144, pp.106-117.

[37]Xinwei H., Huihui N., Zhe, Y., Yi, L., Liuwei, Z., Wei, L., "Mechanical properties of a novel fiber metal laminate based on a carbon fiber reinforced $\mathrm{Zn}-\mathrm{Al}$ alloy composite", Materials Science \& Engineering A (2019), Vol.740-741, pp. 218-225

[38] Sagar D. Patil, D.S.Chavan, M.V.Kavade, "Investigation of Composite Torsion Shaft for Static Structural Analysis using Finite Element Analysis." International Journal of Engineering Research \& Technology, Vol. 1 Issue 7, September - 2012, pp1-5.

[39] Sagar D. Patil, D.S.Chavan, M.V.Kavade, "Investigation of Composite Torsion Shaft for Torsional Buckling Analysis using Finite Element Analysis" IOSR Journal of Mechanical and Civil Engineering, Volume 4, Issue 3 (Nov-Dec. 2012), pp.26-31.

[40] Girish Dutt Gautam, Dhananjay R. Mishra " Firefly algorithm based optimization of kerf quality characteristics in pulsed Nd:YAG laser cutting of basalt fiber reinforced composite" Composites Part B, Volume 176 (2019) pp.107-340.

[41] Dhananjay R. Mishra, Girish Dutt Gautam, Divyanshu Prakash, Abhay Bajaj, Abhishek Sharma, Rajat Bisht, Siddharth Gupta "Optimization of Kerf Deviations in Pulsed Nd:YAG Laser Cutting of Hybrid Composite Laminate Using GRA" FME Transactions, (2020) Volume 48, pp.109-116.

[42] Varun A, Venkaiah N. "Grey relational analysis coupled with firefly algorithm for multiobjective optimization of wire electric discharge machining". J Engineering Manufacturing. 2015; Volume 229 pp.1385-94.

[43] Wolpert DH and Macready WG. No free lunch theorems for optimization. IEEE Transactions on Evolutionary Computation 1997; Volume 1(1): pp. 67-82. 